\title{
To a Problem of a Neuroleptic Cardiomyopathy
}

\author{
Volkov VP* \\ Tver Center of Judicial Examinations, Russia
}

Submission: November 22, 2017; Published: December 04, 2017

*Corresponding author: Volkov VP, Tver Center of Judicial Examinations, Russia, Tel: 7-903-800-11-05; Email: seros2005@mail.ru

\begin{abstract}
The presented review is devoted to generalization of results of own researches of the author on a problem of almost not studied pathology - a neuroleptic (antipsychotic) cardiomyopathy (NCMP). NCMP belongs to secondary specific metabolic dilated cardiomyopathies. It is caused by side cardiotoxic effect of antipsychotic preparations. Many parties of epidemiology, pathogenesis, morphology, clinic and diagnostics of NCMP remain still insufficiently developed.

Results: As showed our researches the development of NCMP passes 3 stages: 1) latent, 2) developed and 3) terminal. Each stage has the clinical features, electrocardiograph signs and certain morphology. The lethal outcome in latent and in developed stages either comes from the intercurrent diseases or is the sudden cardiac death of arhythmogenic genesis. The progressing congestive heart failure serves in a terminal stage as an immediate cause of death. Apparently from our researches morphologically NCMP is characterized by a moderate hypertrophy of heart, expansion of its ventricles and absence of the expressed coronary atherosclerosis. At microscopic research of a myocardium at early stages microcirculation violations come to light. Damages of an extracellular matrix (interstitial oedema and myofibrosis) develop then. Dystrophicdegenerative and atrophic changes of cardiomocytes act into the forefront in a terminal stage. It leads to contractile myocardial dysfunction.
\end{abstract}

Conclusion: On the basis of synthesis of the data obtained in a number of the own researches clinical and morphological criteria of diagnostics of NCMP are allocated and proved. Considering the described features of NCMP the given pathology is allocated in separate independent nosological unit expediently and quite logical.

Keywords: Antipsychotics; Cardiotoxicity; Clinic; Diagnostics; Morphology; Neuroleptic Cardiomyopathy; Nosological Independence

Abbreviations: NCMP: Neuroleptic (antipsychotic) Cardiomyopathy; CHF: Congestive Heart Failure; SCD: Sudden Cardiac Death; QTc: Correct QT

\section{Introduction}

Neuroleptic (antipsychotic) cardiomyopathy (NCMP) is one of serious complications of psychotropic therapy caused by side cardiotoxic effect of antipsychotic preparations [14]. NCMP belongs to secondary specific metabolic dilated cardiomyopathies [5-7]. The disease is characterized by diffusion damage of a myocardium, sharp decrease in its contractile function and as a result the progressing congestive heart failure (CHF) [2,5,6,8-10]. Many parties of epidemiology, pathogenesis, morphology, clinic and diagnostics of NCMP remain still insufficiently developed. The goal of the real review is the short generalization of the results of the own researches of this problem.

\section{Material and Methods}

Our long-term researches are conducted on different material and various methods including statistical (parametric and nonparametric). At macroscopic studying of heart original own organometric approach is applied [11]. The microscopic condition of a myocardium is estimated by means of a morphometric method.

\section{Results}

According to our section data among the died patients with schizophrenia which obligatory component of therapy is reception of antipsychotic preparations the number of the suffering of NCMP (11.4\%) is considerable and statistically significant above than in gross section material on a psychiatric pathological department in general $(2.0 \%)$ [8]. As showed our researches the development of NCMP passes 3 stages: 1) latent, it is clinically completely compensated, 2) developed at which cardiac violations distinctly are defined, but without the expressed signs of $\mathrm{CHF}$, and 3) terminal when the clinic of CHF acts into the forefront [9,12-14]. The lethal outcome in latent and in developed stages either comes from the intercurrent diseases or is the sudden cardiac death (SCD) of arhythmogenic genesis $[5,12,14]$. The last is observed at $44.2 \%$ of the dead of NCMP according to our data $[15,16]$. The 
progressing CHF serves in a terminal stage as an immediate cause of death.

The disease develops slowly and at the beginning is hardly noticeable. In a latent stage it is practically shown by nothing $[5,12,14]$. During this period the complaints of patients have uncertain character or are in general absent. Fatigue and short wind at considerable physical activity is most often noted. Thus it must be kept in mind known difficulties of detection of complaints at mental patients connected both with their inadequate behavior and lack of due criticism to their state and with quite often certain medicament load. In a latent stage of NCMP the findings of the examination are not numerous and aren't specific. The tachycardia serving as almost constant phenomenon at reception of neuroleptics is observed as a rule [1]. De an auscultation in is defined the deafness of cardiac sounds. Poorly the borders of heart are usually changed. An arterial hypo- and a norm tonicity significantly prevail from the arterial pressure. The insignificant arterial hypertension is only approximately in $1 / 3$ cases observed $[5,12]$.

On the electrocardiogram during this period there are most often the following pathological signs:

A. Diffusion muscular changes;

B. Different types of violation of conductivity, in particular the blockade of the left leg of Gis's bunch;

C. Deviation of an electric axis of a heart to the left;

D. Overload of the right departments of the heart;

E. Hypertrophy of the left ventricle [5,6,8-10,17].

In the developed stage the clinic of NCMP is rather distinctly shown, but the signs of terminal CHF are absent or poorly noticeable. The complaints of patients are more certain: weakness, fatigue, heart beating, short wind at moderate physical activity, sometimes passing pains in the cardiac region. By the physical examination the deafness of cardiac sounds, some expansion of the borders of a heart, tachycardia, passing breathlessness notes. During this period the steadily normal or labile arterial pressure equally often meets, but there is a tendency to the moderate increase of it $[5,12]$.

The terminal stage of a current of NCMP is characterized by accession to already listed symptoms of the known manifestations of the increasing CHF: short wind at a rest or the small physical activity, orthopnea posture, the increase of a liver, the peripheral and cavitary oedemata, sometimes an anasarka etc. The heart borders are expanded that is confirmed by the roentgen exploration. The cardiac sounds are deaf. There are almost always a tachycardia and an arrhythmia. The moderate arterial hypertension is observed by a little more than at $1 / 4$ patients, and the arterial pressure constantly exceeds $150 / 100 \mathrm{~mm}$ of mercury at $13.6 \%$ of patients $[5,12]$. On an electrocardiogram in developed and terminal stages of NCMP there are such most dangerous phenomena:
A. Violations of conductivity;

B. Lengthening of an interval of QT in recalculation on Bazett's formula - a correct QT interval (QTc);

C. Overload of the right departments of the heart $[5,6,8$ $10,18]$.

The special attention is deserved by monitoring of parameters of QTc as highly informative indicator in the conditions of a decompensation of the heart $[18,19]$.

Apparently from our researches at the macroscopic (organ) level NCMP is characterized by a moderate cardiac enlargement, a noticeable expansion of ventricles of a heart with some prevalence of dilatation of the left one, absence of the expressed coronary atherosclerosis, especially at the relatively aged persons (45 years and more senior). At microscopic research of a myocardium (tissue and cellular levels) the expressed myofibrosis and small nodular replacement cardiosclerosis, the chronic interstitial oedema, in the beginning hypertrophic and then dystrophic - degenerative and atrophic changes of cardiomocytes come to light. At early stages microcirculation violations come to light. Damages of an extracellular matrix (interstitial oedema and myofibrosis) develop then. Dystrophic-degenerative and atrophic changes of cardiomocytes act into the forefront in a terminal stage.

\section{Discussion}

The high frequency of NCMP revealed on autopsy at the patients accepting antipsychotics testifies to what broad application in medical practice of neuroleptics is the reason of development of the given cardiac pathology in patients with schizophrenia. It is seen from our researches clinical diagnostics of NCMP is difficult as its symptom complex has no peculiar features [17]. On the basis of synthesis of the data obtained in a number of the own researches the clinical criteria of diagnostics of NCMP are allocated and proved $[2,5,6,8,10,17,20]$.

The diagnostic scheme is approximately submitted as follows.

I. Big criteria (absolute):

a) The treatment by neuroleptics;

b) The absence of other cardiac pathology.

II. Small criteria (relative):

a) The cardiac complaints (even minimum);

b) The increase in the sizes of a heart (be percussion and the roentgen exploration);

c) The findings by the physical examination (tachycardia, arrhythmia, deafness of cardiac sounds);

d) The changes of an electrocardiogram (especially the increase in QTS, violations of a rhythm and a conductivity); 


\section{Global Journal of Addiction \& Rehabilitation Medicine}

e) The existence of CHF in the absence of other reasons of its development;

f) The SCD of patients (it is important for posthumous diagnostics).

It is necessary to emphasize that each of the listed signs taken separately out of communication with others isn't specific to NCMP. However in the set these criteria can become a reliable basis for clinical verification of this disease. The long reception of antipsychotic preparations is the main condition forcing to think of NCMP.

There is basis to consider that for diagnostics of NCMP it is enough to have available both big signs and at least two small. However in this direction nevertheless further researches and accumulation of practical experience are necessary. At the same time in our opinion the offered criteria of diagnostics of NCMP and the approximate diagnostic scheme will be able to become useful for the early identification of this serious complication of an antipsychotic therapy in order to its timely corrective treatment.

Posthumous diagnostics of NCMP also causes certain difficulties. They are connected mainly with insufficient development of the morphological criteria allowing the pathologist to diagnose NCMP [21]. The results of the own research of morphology of NCMP executed at the different levels of an organization of an organism light a pathological picture of this disease rather fully. During a morphogenesis of NCMP all structural components of a myocardium (the microcirculatory course, extracellular matrix, cardiomocytes) are deeply damaged that sharply reduces its contractile reserves. The revealed pathological shifts of a microstructure of a cardiac muscle reflect profound tissue changes dystrophicdegenerative, sclerotic and to a lesser extent compensatory and adaptive character which are developed in a myocardium in the course of a morphogenesis of NCMP.

All noted pathological changes are objective reliable morphological features and a material basis of the contractile myocardial dysfunction leading to progressing of fatal CHF eventually [22,23]. As showed our researches each of the found morphological signs in it taken separately aren't specific to NCMP. However in the set the described morphological changes permit enough confidently to diagnose this disease anatomic pathologically $[18,21]$. Thus NCMP possesses all signs of the concept "illness" that is has own epidemiology, etiology, pathogenesis, clinic and morphology.

\section{Conclusion}

Proceeding from told about NCMP this pathology is allocated in separate independent nosological unit expediently and quite logical. On ICD-10 it can be carried to the heading I42.7 "The cardiomyopathy caused by influence of medicines and other external factors" with the additional code reflecting an external cause of illness (a class of antipsychotic preparations) - Y49.3-Y49.5 [5,18].

\section{References}

1. Volkov VP (2010) Cardiotoxicity of phenothiazine neuroleptics (review of literature). Psichiat psychopharmacother 12(2): 41-45.

2. Volkov VP (2009) Phenothiazine dilated cardiomyopathy: some aspects of clinic and morphology. Clin Med 8: 13-16.

3. Buckley NA, Sanders P (2000) Cardiovascular adverse effects of antipsychotic drugs. Drug Saf 23(3): 215-228.

4. Coulter DM, Bate A, Meyboom RHB, Lindquist M, Edwards IR (2001) Antipsychotic drugs and heart muscle disorder in international pharmacovigilance: data mining study. Br Med J 322: 1207-1209.

5. Volkov VP (2013) Clinical characteristic of an antipsychotic cardiomyopathy. In: Volkov VP, editor. Actual problems of therapeutic clinic: collective scientific monograph. Novosibirsk: SibAC 94-116.

6. Volkov VP (2012) Electrocardiographic manifestations of an antipsychotic cardiomyopathy at patients with schizophrenia at stages of its morphogenesis. Upper Volga Med J 10(1): 13-6.

7. Tereshchenko SN, Jaiani NA (2001) Dilated cardiomyopathy today. Heart failure 3(2): 58-60.

8. Volkov VP (2011) To a question of a secondary phenothiazine cardiomyopathy. Clin Med 5: 30-33.

9. Volkov VP (2009) Features of an electrocardiogram at a phenothiazine cardiomyopathy. Upper Volga Med J 7(4): 3-7.

10. Volkov VP (2011) Features of the electrocardiogram at a phenothiazine cardiomyopathy. Clin Med 4: 27-30.

11. Volkov VP (2014) New method of an organometry of heart. In: Volkov VP (Eds.), Paraclinical disciplines: new methods and diagnostic opportunities: collective monograph. Novosibirsk: SibAC 78-100.

12. Volkov VP (2013) Dynamics of arterial pressure at an antipsychotic cardiomyopathy. In: Innovations in science: materials of the XIX ${ }^{\text {th }}$ international correspondence scientific and practical conference (on April 22, 2013). Novosibirsk: SibAC 130-137.

13. Volkov VP (2012) Morphological features of an antipsychotic cardiomyopathy. In: Medicine: calls of today: international correspondence scientific conference. Chelyabinsk 33-36.

14. Volkov VP (2012) Morphometric aspects of a morphogenesis of an antipsychotic cardiomyopathy. Ros J Cardiol 3: 68-73.

15. Volkov VP (2009) Sudden death of patients with schizophrenia. Upper Volga Med J 7(2): 3-7.

16. Volkov VP (2013) Sudden cardiac death at schizophrenia. Mental health 1: 50-4.

17. Volkov VP (2012) Antipsychotic cardiomyopathy. In: Volkov VP Zacharov RI, editors. Pharmacotherapy: new prospects and problems: collective scientific monograph. Novosibirsk: Siberian Association of Consultants 65-84.

18. Volkov VP (2013) Antipsychotic cardiomyopathy: diagnostic approaches and criteria of the diagnosis. Doctor 9: 69-71.

19. De Luna AB (1993) The guidance on a clinical electrocardiogram. M.: Medicine.

20. Volkov VP (2013) Antipsychotic cardiomyopathy: clinicalmorphological criteria of the diagnosis. Curing doctor 10: 77-80.

21. Volkov VP (2012) Antipsychotic cardiomyopathy: pathoanatomical criteria of the diagnosis. In: Medicine questions: theory and practice: materials of the international correspondence scientific and practical conference (on December 03, 2012). Novosibirsk: SibAC 51-56. 
22. Amosova EN (1999) Cardiomyopathies. Kiev: Book plus.

This work is licensed under Creative Commons Attribution 4.0 License DOI: 10.19080/GJARM.2017.04.555649
23. Shumakov VI, Hubutiya MSh, Ilyinsky IM (2003) Dilated cardiomyopathy. Tver: Triad.

\section{Your next submission with Juniper Publishers} will reach you the below assets

- Quality Editorial service

- Swift Peer Review

- Reprints availability

- E-prints Service

- Manuscript Podcast for convenient understanding

- Global attainment for your research

- Manuscript accessibility in different formats

( Pdf, E-pub, Full Text, Audio)

- Unceasing customer service

Track the below URL for one-step submission https://juniperpublishers.com/online-submission.php 